Kapata Arkeologi, 13(2), 151-162

ISSN (cetak): 1858-4101

ISSN (elektronik): 2503-0876

http://kapata-arkeologi.kemdikbud.go.id

\title{
PETUAH-PETUAH LELUHUR DALAM WÉRÉKKADA: SALAH SATU PENCERMINAN KEARIFAN LOKAL MASYARAKAT BUGIS
}

\section{Messages Ancestor in Wérékkada: One of the Reflection Local Wisdom of Buginese Community}

\author{
Mustafa \\ Balai Bahasa Sulawesi Selatan - Indonesia \\ Jalan Sultan Alauddin Km. 7 Talasalapang, Makassar 90221 \\ lamadaremmeng@gmail.com
}

Naskah diterima: 10/05/2017; direvisi: 29/09—16/11/2017; disetujui: 18/11/2017

Publikasi elektronik: 30/11/2017

\begin{abstract}
This paper aim to examine the local wisdom contained in wérékkada. Wérékkada is a classic Buginese literary form that is still lived by those with Buginese Language and culture backgrounds that serve as an adhesive tool for interpersonal relationships and sources of laws and regulations that can tap the heart, mind and command people to be honest, polite courteous, knowing customs, and manners in social life. This paper describes the local wisdom of Buginese culture that is still practiced in society. The approach used in this study uses two theories namely, pragmatic and sociology of literary approach. The methods and techniques used in this study are descriptive methods, which are described the data as it is. Data was collected using recording techniques, interviews, recording, and literature study. The results can be concluded that wérékkada contains local wisdom such as honesty, an advice (wérékkada) which contains the basic foundation in establishing relationships between people, perseverance, which is an advice that gives an overview of the daily behavior of someone who has a price high self, firm, tough, faithful to faith, and obedient principle. Meanwhile, sirik 'malu' is one of the Buginese way of life, which aims to maintain personal dignity, others or groups.
\end{abstract}

Keywords: oral literature, local wisdom, ancestral wisdom

\begin{abstract}
Abstrak
Tulisan ini bertujuan untuk mengkaji kearifan-kearifan lokal yang terdapat dalam wérékkada. Wérékkada adalah salah satu bentuk sastra klasik Bugis yang hingga kini masih dihayati oleh masyarakat berlatar belakang bahasa dan budaya Bugis yang berfungsi sebagai alat perekat hubungan antar individu dan sumber hukum serta peraturan yang mampu mengetuk hati, pikiran dan memerintahkan orang untuk berlaku jujur, berperilaku sopan santun, tahu adat istiadat, dan tata krama dalam hidup bermasyarakat. Tulisan ini menggambarkan kearifan lokal budaya Bugis yang hingga kini masih berlaku di dalam masyarakat. Pendekatan yang digunakan dalam kajian ini menggunakan dua teori yaitu, pendekatan pragmatik dan sosiologi sastra. Metode dan teknik yang digunakan dalam kajian ini adalah metode deskriptif, yaitu memaparkan sebagaimana adanya. Pengumpulan data, digunakan teknik pencatatan, wawancara, perekaman, dan studi pustaka. Hasil penelitian menyimpulkan bahwa wérékkada dapat mengandung kearifan lokal tentang kejujuran. Petuah-petuah atau wérékkada berisi landasan pokok dalam menjalin hubungan antar sesama, keteguhan, memberikan gambaran dari tingkah laku sehari-hari seseorang yang memiliki harga diri yang tinggi, tegas, tangguh, setia pada keyakinan, dan taat asas. Sementara itu, sirik 'malu,' adalah salah satu pandangan hidup orang Bugis yang bertujuan untuk mempertahankan harkat dan martabat pribadi, orang lain atau kelompok.
\end{abstract}

Kata kunci: sastra lisan, kearifan lokal, petuah-petuah leluhur 


\section{PENDAHULUAN}

Sastra adalah sebuah karya cipta khas yang dapat memperkaya dan memperluas cakrawala pembacanya. Karya sastra mengandung nilai-nilai yang dapat memperbaiki pandangan hidup, mempertajam akal, dan memperhalus budi, sehingga dapat membuat kehidupan menjadi lebih beradab dan dapat membuat pembacanya lebih peka dalam menghadapi berbagai perkembangan dan perubahan di dalam kehidupannya. Wérékkada adalah salah satu bentuk sastra Bugis, hingga saat ini masih dihayati oleh masyarakat yang berlatar Bahasa Bugis. Jenis sastra ini merupakan warisan budaya Bugis yang diturunkan dari satu generasi ke generasi berikutnya. Isinya mengandung bermacam-macam petuah yang dapat dijadikan pegangan dalam menghadapi berbagai masalah kehidupan, baik kehidupan duniawi maupun ukhrawi. Dalam wérékkada ditemukan petunjuk tentang pendidikan budi pekerti, nilai-nilai moral, dan keagamaan.

Sastra daerah merupakan bukti hitoris kreativitas masyarakat daerah. Sehubungan dengan itu, sastra daerah sebagai salah satu bagian kebudayaan daerah berkedudukan sebagai wahana ekspresi budaya yang di dalamnya terekam antara lain pengalaman estetik, religius, dan sosial politik masyarakat etnis yang bersangkutan. Oleh karena itu, upaya berkesinambungan untuk menjaga, menjamin, dan meningkatkan mutu sastra perlu diperhatikan dengan sungguh-sungguh (Alwi \& Sugono, 2011: 105).

Sastra mengandung ilmu, kehidupan, dan nada keindahan. Oleh karena itu, sastra dapat menjadi media pembelajaran tentang ilmu, dan kehidupan. Hal itu telah terjadi beradab-abad yang lalu. Sugono dalam Harianto (2004) menyampaikan, untuk lebih meningkatkan peran sastra tersebut dalam kehidupan generasi ke depan, Badan Bahasa berupaya meningkatkan pelayaan kepada anak-anak Indonesia tentang kebutuhan bacaan sebagai salah satu upaya peningkatan minat baca dan wawasan serta pengetahuan dan apresiasi seni terhadap karya sastra Indonesia (Harianto, 2004: iii). Kekayaan nasional berupa sastra Indonesia dan sastra daerah itu sangat beragam. Keanekaragaman tampak dalam bahasa yang digunakannya, yaitu bahasa daerah yang jumlahnya sangat banyak. Keanekaragaman itu tampak pula dalam khazanahnya dan perkembangan yang dialami oleh sastra itu. Di samping keragaman, dalam sastra Indonesia dan sastra daerah juga terdapat kesamaan. Kesamaan ini pun patut mendapat perhatian karena kesamaan dan keragaman ini terkait dengan kebudayaan Indonesia secara keseluruhan juga memiliki keadaan demikian. Manfaat sastra daerah atau sastra Nusantara bagi masyarakat tentu saja amat besar. Berbagai ajaran moral dapat disampaikan melalui sastra. Dalam berbagai upacara, sastra dimanfaatkan sebagai hiburan. Selain itu, apa yang disajikan oleh sastra itu sangat bermanfaat bagi kehidupan manusia karena sastra itu sendiri mengandung nilai budaya, moral, hukum dan sebagainya.

Sejalan dengan hal tersebut di atas, tulisan ini mengangkat karya sastra lisan Bugis yang hingga kini masih dipelihara dengan baik, yaitu wérékkada. Wérékkada adalah pesan-pesan atau petuah-petuah agar selalu bertingkah laku baik terhadap diri sendiri, orang lain, dan ciptaan Tuhan lainnya. Tak berlebihan bila dikatakan wérékkada merupakan salah satu warisan budaya bangsa yang perlu mendapat perhatian. Bukti historis kreativitas masyarakat daerah merupakan wahana ekspresi budaya yang di dalamnya terekam pengalaman estetik, religius, dan sosial politik masyarakat etnis yang bersangkutan. Generasi mendatang dapat mengetahui bahwa nenek moyang kita dahulu meninggalkan salah satu warisan budaya yang sangat berharga. Penelitian yang lebih terarah dan mendalam merupakan salah satu upaya guna menyelamatkan dan melestarikan budaya Bugis. Kegiatan tersebut dimaksudkan bukan hanya untuk memperkaya sastra dan khasanahnya, melainkan juga sebagai modal dasar dalam mengapresiasikan sastra khususnya sastra daerah.

Wérékkada merupakan cerminan kehidupan dalam masyarakat lama. Dalam hal ini, manusia tunduk kepada peraturan-peraturan dan tradisi. Hal ini dilakukan karena mereka menginginkan kehidupan yang stabil, kokoh, dan harmonis. Ciri manusia sebagai individu dalam masyarakat adalah hidup dalam kebersamaan. Segala macam masalah menjadi masalah bersama dan harus diselesaikan bersama pula. Dalam masyarakat seperti itu ditemukan nilainilai yang menjadi pandangan dalam kehidupan bersama. Nilai-nilai yang dianggap baik itu adalah nilai-nilai yang dapat menjadikan manusia dipandang sebagai manusia ideal dalam masyarakat. Berbagai bentuk peninggalanpeningglan leluhur dalam bentuk lisan harus 
dimanfaatkan dengan baik, karena menyimpan banyak nilai-nilai kearifan lokal yang sulit ditemukan di dalam bukti atau dokumen tertulis (Marihandono, 2015: 83-84). Dengan demikian, dalam tulisan ini dirumuskan pertanyaan penelitian, yaitu bagaimanakah kearifan lokal masyarakat Bugis yang terkandung di dalam wérékkada?

Tulisan ini bertujuan mengangkat kearifan lokal masyarakat Bugis yang terdapat di dalam wérékkada sebagai upaya inventarisasi sastra daerah Bugis yang sudah semakin jarang diketahui oleh generasi muda dewasa ini. Selain itu, untuk menghasilkan sebuah risalah penelitian yang secara garis besar berisi sejumlah wérékkada atau petuah-petuah leluhur beserta kearifan lokal yang terkandung di dalamnya.

Sastra diciptakan oleh sastrawan untuk dinikmati, dihayati, dipahami, dan dimanfaatkan oleh masyarakat. Sastra adalah lembaga sosial yang menggunakan bahasa sebagai media untuk menampilkan gambaran kehidupan. Horatius berpendapat bahwa fungsi sastra hendaknya memuat dulce (indah) dan utile (berguna). Konsep ini sejalan dengan pendapat Poe (Wellek dan Warren, 1993: 24-25) bahwa fungsi sastra adalah dedactic-heresy, yaitu menghibur dan sekaligus mengajarkan sesuatu. Karya sastra hendaknya membuat pembaca merasa nikmat dan sekaligus dapat memetik pelajaran. Hal ini seperti dinyatakan Hall (1979), bahwa karya sastra hendaknya memiliki fungsi use and gratifications, yaitu berguna dan memuaskan pembaca (Hall, 1979: 131). Pendapat-pendapat ini memberikan gambaran bahwa pembaca harus mendapatkan manfaat yang mampu mengubah dirinya (Endraswara, 2011: 116-117). Karya sastra yang menyenangkan tentu saja bukan pengalaman yang biasa, melainkan pengalaman bersifat seni dan pengalaman besar tentang pandangan hidup, renungan tentang baik buruk, moral yang tinggi, dan sebagainya. Oleh karena itu, pengalaman jiwa yang tinggi itu dapat memperkaya jiwa dan batin pembaca sehingga berguna bagi kehidupannya. Itulah guna dan fungsi hakikat karya sastra pada khususnya dan karya seni pada umumnya (Pradopo, 2003: 45).

Dalam posisinya sebagai penikmat, pembaca akan meresepsi dan sekaligus memberikan tanggapan tertentu terhadap karya sastra. Pembaca sebagai penyelamat, maka mau menerima kehadiran sastra, juga akan meresepsi dan selanjutnya melestarikan dengan cara mentransformasikan. Berkaitan dengan aspek pragmatik, teks sastra dikatakan berkualitas apabila memenuhi keinginan pembaca. Betapa pun hebat sebuah karya sastra, jika tidak dapat dipahami oleh pembaca boleh dikatakan teks tersebut gagal. Teks sastra tersebut hanya tergolong black literature atau diistilahkan sastra hitam yang hanya bisa dibaca oleh pengarangnya. Karya semacam ini hanya "menara gading" yang tidak pernah akrab dengan pembaca. Karena itu aspek pragmatik terpenting adalah ketika teks sastra itu mampu menumbuhkan kesenangan bagi pembaca. Pembaca sangat dominan dalam pemaknaan karya sastra (Endraswara, 2011: 115).

Adapun beberapa hasil penelitian sastra Bugis yang pernah dikaji antara lain sebagai berikut: (1). Nilai Kearifan Lokal Pantun Sindiran (Appareresang) Bugis: Tinjauan Hermeneutik oleh Uniwati (2012). (2). Pendidikan Nilai dan Karakter dalam Pappaseng: Representatif Norma dan Falsafah Hidup Masyarakat Bugis oleh Syamsudduha (2012). (3) Sastra Bugis Sebagai Dokumen Budaya oleh Tang (2012), dan (4) Nilai-Nilai Budaya yang Terkandung dalam "Silasa" oleh Mustafa (2016).

\section{METODE}

Metode yang digunakan dalam penelitian ini adalah metode deskriptif. Kearifan lokal yang terdapat dalam karya sastra itu dipaparkan sebagaimana adanya. Untuk lebih lengkapnya pernyataan itu disertai dengan kutipan teks wérékkada yang mengacu pada kearifan lokal yang dimaksud. Data yang diperoleh disajikan dalam bentuk deskripsi. Dalam pengumpulan data, digunakan teknik pencatatan, perekaman, wawancara, dan studi pustaka. Jawaban informan atas pertanyaan atau rangsangan yang disusun dalam instrumen dicatat dan direkam di lapangan. Studi pustaka digunakan untuk menjaring data tertulis sebanyak-banyaknya melalui buku-buku atau tulisan yang relevan dengan tulisan ini. Teknik wawancara dimaksudkan untuk medapatkan informasi yang diperlukan dari informan dengan mengajukan pertanyaan terbuka sesuai dengan situasi ketika wawancara berlangsung. Hal ini dilakukan untuk memperoleh data lisan sekaligus mempelajari pemanfaatan wérékkada dalam komunikasi.

Dalam mengkaji wérékkada, tulisan ini mengacu pada sejumlah referensi terkait. Petuah- 
petuah dalam bentuk wérékkada banyak ditemukan dalam buku yang ditulis oleh Fachruddin, Lagausi, \& Nur (1985), yaitu Pappasenna To Maccae Ri Luwuq sibawa Kajao Laliqdong Ri Bone (Transliterasi dan Terjemahannya ke dalam Bahasa Indonesia) dan referensi pendukungnya adalah buku-buku sastra yang ada kaitannya dengan pembahasan yang telah ditentukan dalam tulisan ini.

\section{HASIL DAN PEMBAHASAN}

Wérékkada adalah salah satu bentuk sastra klasik Bugis yang sekaligus sebagai warisan budaya masyarakat Bugis yang banyak mencerminkan kearifan lokal. Kearifan lokal yang menjadi fokus utama meliputi bawaan hati yang baik, konsep pemerintahan yang baik (good governance), demokrasi, motivasi berprestasi, kesetiakawanan sosial, kepatutan, dan penegakan hukum. Kearifan itu memiliki kedudukan yang kuat dalam kepustakaan Bugis dan masih sesuai dengan perkembangan zaman (Said, 2015). Kearifan lokal yang tercermin dalam wérékkada antara lain kejujuran, keteguhan, dan sirik atau harga diri.

\section{Kejujuran}

Kejujuran merupakan landasan pokok dalam menjalin hubungan dengan sesama manusia dan merupakan salah satu faktor yang sangat mendasar di dalam kehidupan. Tanpa kejujuran, mustahil akan tercipta hubungan yang baik dengan sesama manusia. Untuk mengemban suatu amanah atau menjadi seorang pemimpin, kejujuran itu sangat dibutuhkan seperti yang tertera dalam wérékkada berikut.

Makkedai Kajao Laliqdong: Aga sio, Arumponé, muaseng tettaroi nreqba aleqbiremmu, patokkong pulanai alekbireng mubakurié, ajaq natatteré-teré tau teqbeqmu, ajaq napada wenno pangampo waramparang mubakurié?"

Makkedai Arumponé: "Lempué Kajao

Enrengngé accaé"

Makkedai Kajao Laliqdong: "Iatona

ritu Arumponé, Tania to ritu."

Makkedai Arumponé: "Kéga palék,

Kajao?"

Makkedai Kajao Laliqdong: "Ia inanna waramparangngé Arumponé, tettaroéngi tatteré-teré tau tekbek é, temmatinropi matanna arungngé ri esso ri wenni, nnawa- nawai adécéngen-na tanana, natangngai olona munrinna gauk é, napogauq $i$. Maduanna, maccapi mpinru ada arung mangkauk é. Matellunna, maccapi duppai ada arung mangkauk é. Maeppana, tengngallupannge surona ada tongeng." (Fachruddin, Lagausi, \& Nur, 1985: 8)

\section{Terjemahan}

"Berkata Kajao Laliqdong: "Apa gerangan, wahai Arumpone, yang menurut pendapatmu tidak membiarkan rebah kemuliaanmu, yang senantiasa menegakkan kemuliaan yang engkau pelihara, supaya tidak bercerai-berai rakyatmu, tidak seperti penghambur harta benda yang engkau simpan baik-baik?"

Berkata Arumpone: "Kejujuran bersama kepandaian, nenek!"

Berkata Kajao Laliqdong: "Itulah kiranya Arumpone, tetapi juga bukan demikian."

Berkata Arumpone: "Yang manalah kiranya, wahai Nenek?"

Berkata Kajao Laliqdong: "Adapun sumber segala harta benda, Arumpone, yang tidak membiarkan rakyatnya bercerai-berai, ialah tidak tidur mata seorang raja (pemimpin) siang dan malam merenungkan kebaikan negerinya; ditinjaunya pangkal kesudahan sesuatu perbuatan, barulah dilakukan; Kedua, seorang raja yang memerintah harus pandai merangkai kata; Ketiga, seorang raja yang memerintah harus pandai menyambut kata; Keempat, duta negerinya tidak pernah lupa mengatakan perkataan benar."

Wérékkada di atas yang disampaikan melalui dialog antara Arumpone dengan Kajao Laliqdong menekankan tentang kejujuran dalam menjalankan amanah yang dipercayakan oleh orang banyak atau masyarakat. Menurut Arunpone, kemuliaan seseorang bukan dinilai dari jabatan atau harta benda yang dimiliki, melainkan yang memelihara semua itu adalah kejujuran. Kemudian dilanjutkan dengan pernyataan bahwa kesuksesan seorang raja atau pemimpin tidak terlepas dari para duta-duta negerinya atau para pembantunya yang tidak pernah lupa mengatakan perkataan benar. Maksudnya hanya orang-orang jujur saja yang selalu mampu mengucapkan kata-kata benar.

Jaminan suatu kejujuran adalah seruan yang inti dasarnya adalah melarang mengambil sesuatu yang bukan miliknya (Jemmain, 2016: 
168). Dengan kata lain, orang yang tidak suka mengambil sesuatu yang bukan miliknya adalah orang-orang jujur. Misalnya, bila kita menemukan ada kayu yang disandarkan disuatu tempat, itu berarti kayu itu sudah ada pemiliknya. Begitu juga kayu yang sudah ditata ujung pangkalnya juga sudah ada pemiliknya. Jadi wajarlah kalau barang-barang seperti itu dilarang untuk diambil.

\section{Makkedai Arumponé: "Aga tanranna namaraja tanaé, Kajao?}

Makkedai Kajao Laliqdong: "Dua tanranna namaraja tanaé, Arumponé. Séuani, malempui namacca arung mangkauk é. Maduanna, tessisala-salaié ri lalempanua."

Makkedai Arumponé: "Aga ttula pattaungeng, Kajao?"

Makkedai Kajao Laliqdong: "Naia ttulaé pattaungeng Arumponé.

Séuani nakko matanré cinnai arung mangkauq é.

Maduanna, nakko nateriwi waram-parang tomaqbicaraé.

Matellunna, nakko sisala-salai taué ri lalempanua. Tanranna toparo, nakko maéloni biccuq tana marajaé." (Fachruddin, Lagausi, \& Nur, 1985: 9)

Terjemahan

"Berkata Arumponé: "Apa tanda

kebesaran suatu negeri, wahai Nénék?"

Berkata Kajao Laliqdong:"Dua tanda

negeri menjadi besar, Arumponé:

Pertama, raja yang memerintah jujur lagi

pandai. Kedua, tidak terjadi silang

sengketa dalam negeri."

Berkata Arumponé: "Apa yang

menggagalkan panen (tahunan) wahai

Nénék?"

Berkata Kajao Laliqdong: “Adapun yang menggagalkan panen (tahunan) Arumponé, ialah pertama, jika raja yang memerintah terlalu tinggi pengharapan. Kedua, jika penegak hukum sudah mau menerima suap. Ketiga, jika terjadi silang sengketa dalam negeri, itu pula tandanya jika suatu negeri besar akan menjadi kecil.”

Dalam kutipan dialog di atas Kajao Laliqdong menegaskan bahwa negeri bisa besar kalau pemimpinnya jujur dan pandai. Kalau orang-orang pandai tidak jujur, bisa jadi kepandaiannya disalahgunakan sehingga dapat merugikan orang lain, dan dalam lingkup yang lebih luas lagi bisa merugikan negaranya sendiri. Kejujuran merupakan landasan pokok dalam menjalin hubungan dengan sesama manusia, dan merupakan falsafah salah satu faktor yang sangat mendasar di dalam kehidupan. Selanjutnya tidak terjadi silang sengketa dalam negeri. Hal yang sering juga menimbulkan silang sengketa adalah ketidakjujuran. Kalau salah satu pihak merasa didzalimi, dibohongi, atau diperlakukan dengan tidak jujur, pada saat itulah timbul kesalahpahaman serta silang sengketa dan tidak tertutup kemungkinan bisa menimbulkan kekacauan dalam negeri.

Selanjutnya Kajao Laliqdong mengatakan bahwa yang menggagalkan panen adalah jika raja yang memerintah terlalu tinggi pengharapan. Maksudnya adalah pemimpin yang mengharapkan sesuatu di luar kemampuannya sehingga untuk mendapatkannya bisa saja menghalalkan segala macam cara termasuk cara-cara ketidakjujuran. Selanjutnya penegak hukum sudah mau menerima suap. Kalau penegak hukum mau menerima suap berarti penegak hukum sudah tidak jujur. Kalau penegak hukum tidak jujur bisa jadi berat sebelah, dan tidak tertutup kemungkinan yang salah dibenarkan dan yang benar disalahkan. Hal seperti ini bisa menimbulkan kekacauan di dalam negeri yang sekaligus mengerdilkan negeri bukan memakmurkan atau membesarkan negeri.

Makkedai Arumponé: "Aga tanranna asawéng asé, Kajao?"

Makkedai Kajao Laliqdong: "Tellu tanranna nasawéng asé Arumponé. Séuani, komalempui arung mangkauké. Maduanna, nakko mappémmaliwi arung mangkauk é, enrenngé tomaqbicara é. Matellunna, mattau séuwapi tauéri lalempanua." (Fachruddin, Lagausi, \& Nur, 1985: 10)

Terjemahan

"Berkata Arumpone: "Apa tandanya jika panen padi akan berhasil, wahai Nenek?"

Berkata Kajao Laliqdong: "Ada tiga tandanya jika panen padi akan berhasil baik, Arumpone."

Pertama, jika raja yang memerintah jujur.

Kedua, jika berpantang (pemali) raja yang memerintah beserta penegak hukum dalam negeri. 
Ketiga, bersatu seluruh rakyat dalam negeri."

Kutipan dialog di atas menggambarkan bahwa kejujuran itu sangat luar biasa pengaruhnya. Panen padi akan berhasil dengan baik apabila raja yang memerintah jujur. Maksudnya kalau panen padi berhasil maka kehidupan rakyat sejahtera karena penghasilan mereka meningkat. Jadi kalau raja yang memerintah jujur, maka rakyat sejahtera dan tenteram. Jika raja dan penegak hukum berpantang, maksudnya raja dan penegak hukum jujur pantang menerima sogokan, pemerintahan bersih dan jujur maka rakyat di dalam negeri tenteram dan bersatu.

Makkedai torioloé: "Naia riasenngé nawanawa patuju, sanrépi ri awaraningengngé, namadécéng. Naia awaraningengngé, sanrépi ri nawa-nawa patujué, namadécéng. Naiaro gauk é duanrupaé, lempu manengpa natettongi, namadécéng."

Makkedai tomatoaé: "Nakko engka muéloreng napogau taué, rapangngi lopi. Maélopo ttonangiwi, mupatona-ngianngi taué. Ianaro riaseng malempu makkuaé. (Fachruddin, Lagausi, \& Nur, 1985: 10)

Terjemahan

"Berkata orang tua-tua: "Adapun yang dimaksudkan dengan pikiran yang bermanfaat, ialah harus ia bersandar pada keberanian, barulah ia akan baik. Adapun keberanian itu haruslah bersandarkan pikiran yang bermanfaat, barulah ia akan baik. Adapun perbuatan dua jenis itu, semuanya harus tegak pada kejujuran, barulah ia akan baik."

Kata orang tua-tua: "Sekiranya ada sesuatu yang engkau kehendaki dilakukan oleh orang lain, andaikanlah hal itu sebagai perahu. Jika engkau sendiri bersedia menumpanginya, barulah engkau menyuruh orang lain menumpanginya, yang demikian itulah yang disebut jujur."

Kutipan kata-kata bijak orang tua-tua dahulu di atas menggambarkan bahwa semua pekerjaan akan baik apabila bersandar pada kejujuran. Pikiran yang bermanfaat dan keberanian menjadi baik, jika bersandar pada kejujuran. Selanjutnya orang tua-tua mengatakan bahwa jadikanlah takaran dirimu sendiri apabila ada sesuatu hal yang engkau kehendaki dilakukan oleh orang lain. Jangan perintahkan orang lain melakukan apabila engkau tidak sanggup melakukannya. Demikian itulah yang disebut kejujuran. Jadi, jika menginginkan agar semua aktifitas berjalan baik dan berhasil, maka harus bersandar pada kejujuran.

Orang tua berpesan kepada anak-anaknya bahwa cara mendidik anak-anak adalah memberikan contoh perilaku kejujuran, karena anakanak akan meniru apa yang sering dilakukan orang tuanya. Orang tua juga menyadari bahwa untuk berbuat jujur itu tidak mudah, harus melatih diri atau membiasakan diri untuk berbuat jujur. Kejujuran itu ibarat burung liar kalau tidak diketahui penjinaknya sangat sulit untuk menangkapnya. Penjinak kejujuran itu adalah kewaspadaan, ketelitian, dan kehati-hatian. Untuk menjadi orang jujur harus waspada, teliti, dan hati-hati dalam bertindak dan bertutur kata. Orang yang memiliki tiga hal tersebut selalu terlindungi, seolah-olah berada di dalam kotak besi tidak ada yang bisa mengganggu. Tuhan senantiasa melindungi.

Orang-orang jujur memang selalu berkata benar dan sulit terpengaruh ke arah yang bertentangan dengan kata hatinya. Orang jujur memang memiliki rasa malu yang sangat tinggi dan tabah menghadapi berbagai cobaan. Di samping itu, biasanya pikiran-pikirannya cemerlang dan ramah dalam pergaulan tidak membedabedakan orang. Orang-orang yang takut kepada Dewata (Tuhan) pasti selalu berkata jujur, berbuat baik, dan tidak akan menipu orang lain. Selain itu, ia selalu hati-hati dalam bertindak dan bersungguh-sungguh dalam bekerja. Orang berani memang tidak takut tampil di depan untuk mengayomi. Begitu juga tidak takut tinggal di belakang untuk menjaga dan melindungi. Ia juga siap menerima berita baik ataupun berita buruk, serta tidak gentar berhadapan dengan musuh.

\section{Keteguhan}

Keteguhan pendirian dalam bahasa Bugis disebut getteng. Kata getteng meliputi banyak pengertian, di antaranya, tegas, tangguh, setia pada keyakinan, dan taat asas. (Sikki, 1995: 30). Kalau memperhatikan sumber keteguhan itu, kita akan menemukan nilai luhur yang mendahuluinya, yakni sikap jujur dan keberanian. Tidak mungkin ada keteguhan selama kita diliputi rasa keragu-raguan. Padahal, keragu-raguan timbul 
sebagai akibat perbuatan yang tidak diyakini kebenarannya.

Keteguhan ini dapat dilihat dari tingkah laku sehari-hari orang yang memiliki harga diri, keyakinan dan tanggung jawab. Orang yang mempunyai rasa harga diri tercermin dalam tindakannya yang selalu menepati janji. Menaati keputusan yang telah ditetapkan adalah penjelmaan watak orang yang tetap pendirian. Berikut dikemukakan beberapa wérékkada yang menggambarkan kearifan lokal Masarakat Bugis dalam bentuk keteguhan.

"Makkedai Kajao Laliqdong: "Ia ritu adek é, Arumponé, péasseriwi arajanna arung mangkauk é; ia tonasappoi pangkaukenna toppégauk, ia tona nasanrési to madodonngé. Naia bicaraé, iana passaranngi assisalangenna to mangkagaé. Naia rapanngé, iana passéajinngi tana masséajinngé.

"Nakko marusaqni Arumponé adeké, temmasseqni ritu arajanna arung mangkauk é, masolang toni tanaé. Narékko temmagettenngi bicaraé, masolangni ritu jemma tekbek é. Narékko temmagettengni rapanngé, ianaritu Arumponé mancaji assisalangeng; gaégaénna ritu mancaji musu, musuéna ritu mancaji assiuno-unong. Sabaq makkuannanaro Arumponé, nariéloreng riatutui adeq é kuétopa bicara, enrenngé rapanngé, sibawa wariq é." (Fachruddin, Lagausi, \& Nur, 1985: 10).

\section{Terjemahan}

"Berkata Kajao Laliqdong: "Adapun adat itu, Arumpone, ia memperkukuh kebesaran raja yang memerintah, ia juga yang mencegah perbuatan orang yang tidak bertanggung jawab, juga menjadi sandaran orang lemah. Adapun hukum itu ia memisahkan perselisihan orang yang bertengkar. Adapun rapang (aturan perumpamaan yang diambil dari peristiwa yang sudah pernah terjadi) itu ialah yang mempersaudarakan negeri yang berkerabat.

"Jika rusak adat itu Arumpone, tak akan kukuh lagi kebesaran raja yang memerintah. Jika sudah tidak tegas lagi peradilan maka binasalah rakyat jelata. Jika rapang sudah tidak tegas lagi Arumpone, itulah menjadi sumber pertentangan. Kejadian serupa itu, menjadi pangkal permusuhan dan permusuh- an menjadi pangkal saling membunuh. Oleh sebab itu Arumpone, maka adat, hukum (bicara), rapang (undang-undang), dan wariq (aturan perbedaan pangkat kebangsaan) itu dipelihara."

Dari kutipan wérékkada di atas kita mendapat gambaran bahwa sejak dahulu orangorang tua masyarakat Bugis sudah menekankan betapa pentingnya sikap ketegasan kepada anak cucunya. Mereka juga berpesan agar anak cucunya senantiasa menjaga dan memelihara adat, karena adat itu merupakan sumber kekuatan pemerintahan. Selain itu, yang tidak kalah pentingnya di sini adalah ketegasan dalam peradilan. Sejak dahulu para leluhur masyarakat Bugis sudah menegaskan kepada anak cucunya betapa pentingnya ketegasan dalam peradilan atau dengan kata lain betapa pentingnya penegakan hukum. Hukum harus ditegakkan dengan seadil-adilnya agar tidak menimbulkan ketidakpuasan bagi masyarakat yang bersengketa.

Ungkapan-ungkapan yang disampaikan dalam wérékkada di atas mengenai pertentangan, permusuhan, dan pembunuhan sering kita saksikan terjadi di tengah-tengah masyarakat saat ini akibat kurang tegasnya pengambil kebijakan. Hukum bisa menjadi sumber malapetaka apabila tidak ditegakkan dengan baik. Orang bisa saling membunuh apabila hukum tidak dilaksanakan dengan adil. Hal ini sudah disadari oleh para leluhur masyarakat Bugis sejak dahulu. Gambaran ini dapat dilihat dalam kutipan wérékkada di atas.

Makkedatopi torioloé: "Nakko mappauko, inngeranngi adek é, enrenngé rapanngé, muénngerangtoi gauk muasenngé patuju, naia muparanrengi ada, mupasitai ponna cappaqna adaé nainappa mupoada. Apak iaritu ada madécénngé, enrenngé gauk madécénngé adekpa natettongi namadécéng, enrenngé napatuju. Muparionronai gaukmu iamaneng, enrenngé ada-adammu. Apak munitu muaseng patuju gaukmu enrenngé ada-adammu natania onrona naonroi, salamui." (Fachruddin, Lagausi, \& Nur, 1985: 12).

Terjemahan

"Berkata juga orang tua-tua: "Jika engkau berkata, ingatlah adat serta hukum 
perumpamaan dan ingat pula perbuatan yang engkau anggap benar, dan itulah yang engkau pakai sebagai landasan kata; lalu cocokkanlah pangkal dan ujung perkataan itu, barulah engkau mengatakannya. Sebab adapun katakata yang baik serta perbuatan yang baik itu, pada adatlah ia berdiri, maka ia akan baik serta bermanfaat. Tempatkanlah semua perbuatanmu serta perkataanmu pada tempat-nya yang benar. Demikian, walaupun engkau menganggap perbuatan dan perkataan itu benar tetapi jika ia tidak pada tempatnya yang benar, maka ia akan salah juga."

Kutipan werékkada di atas memberikan gambaran kepada kita bahwa para leluhur masyarakat Bugis teguh pada keyakinan berpegang pada adat dan hukum. Setiap langkah dan ucapannya senantiasa berlandaskan pada adat dan hukum. Setiap kata dan perbuatannya nanti dianggap baik kalau berlandaskan pada adat dan hukum. Mereka hati-hati dalam bertindak, setiap apa yang akan dilakukan dia melihat dan memikirkan ujung dan pangkal perbuatan itu apakah baik atau tidak, apakah menguntungkan atau tidak baru bertindak. Kesemuanya itulah yang akan disampaikan kepada anak cucunya melalui werékkada ini.

Makkedatopi Arung Bila: Agguruiwi gaukna towaranié, enrenngé ampéna. Apak ia gaukna towaranié, seppuloi wuwangenna. Séua тиa jana. Jajini aséra décénna. Ia muaro nariaseng maja céqdié, apag matéi. Naému topéllorenngé maté muto. Apak désa temmaté sininna makkényawaé. Naia décénna towaranié, séuani, tettakini napoléi ada maja, enrenngé ada madécéng. Maduanna dé najampangiwi karébaé. Naéngkalinga muisa, naé napasiloanngi sennang. Matellunna temmataui ri palao riolo. Maeppana temmataui ripaonro ri munri. Mali-manna temmataui mita bali. Maenenna ri asirii. Mapitunna rialai passappo ri wanuaé. Maruana matinului pajaji passurong. Masérana rialai pakdekba tomawatang, bettuanna nakko engka tomatojo iana risuro nrekko i. (Fachruddin, Lagausi, \& Nur, 1985: 24).

Terjemahan

"Berkata lagi Arung Bila: "Pelajarilah tingkah orang berani serta sifatnya. Sebab perbuatan orang berani itu ada sepuluh jenis. Hanya satu kejelekannya, jadi sembilan kebaikannya. Dikatakan jelek yang satu itu karena ia meninggal. Tetapi biar orang penakut mati juga. Karena semua yang bernyawa tidak ada yang tidak mati. Adapun kebaikan orang berani, yaitu Pertama, tidak terkejut mendengar kabar buruk maupun kabar baik. Kedua, tidak menghiraukan kabar itu. Ia tetap mendengarnya, tetapi ia menyertainya dengan ketenangan. Ketiga tidak takut ditempatkan di depan. Keempat tidak takut ditempatka di belakang. Kelima tidak takut melihat lawan. Keenam disegani. Ketujuh dijadikan pelindung negeri. Kedelapan rajin melaksanakan perintah. Kesembilan dijadikan penakluk orang kuat, artinya kalau ada orang keras kepala dialah yang diminta menundukkannya."

Kutipan werékkada di atas memperlihatkan para leluhur masyarakat Bugis sangat mengagumi orang-orang pemberani dan mengharapkan anak cucunya meniru atau mempelajari sifat-sifatnya. Pada umumnya orang-orang pemberani tegas, teguh pada keyakinan tidak mudah goyah. Orang-orang pemberani selalu siap menghadapi berbagai tantangan. Mereka para pemberani konsisten dengan sikapnya, tidak gentar menerima kabar baik maupun kabar buruk. Selalu siap mau ditempatkan di depan atau di belakang.

Dari ungkapan di atas dapat diketahui, bahwa orang pemberani menurut pandangan orang Bugis ialah bukan saja yang berani berkelahi, tetapi yang teguh pendirian dan tak mempercayai kabar sebelum ada bukti, berani membela negaranya, kesatria memberantas kesewenang-wenangan, dan rajin melaksanakan tugas yang dipercayakan.

"Makkedai La Basok: "Aga palorong
wélareng, pakdaung raung kaju?"
Makkedai Tomaccaé ri Luwuk: "Ripa-
riajanngi ri ajanngé, riparilaui ri laué
riparimanianngi rimanianngé, ripari-
asék i ri aséq é ripariawai ri awaé."
"Aga pasawé tau, Nénék, pakbija
olokolkq?" "Iana ritu gettenngé. Eppa gaukna
gettenngé.Séuani, tessalaié janci enrenngé
tessorosi ulu ada. Maduanna tellukkaé anu
pura enrenngé teppinraé assituruseng.


Matellunna narékko maqbicarai, parapi napajajiwi.

"Aru saqbinna gettenngé. Séuani, teppalekbié ada. Maduanna tekkurangié ada. Matellunna palettuq é passurong. Maeppana poadaé ada patuju. Mali-manna pogauk é gauq patuju. Maenenna pogauk é gauk makkenna tuttureng, enrenngé ada-adanna. Mapitunna ssaroi masé ri silasanaé. Maruana pakkatuai aléna ri silalennaé. (Fachruddin, Lagausi, \& Nur, 1985: 26)

\section{Terjemahan}

"Berkata La Basoq: Apa yang menjalin persaudaraan, dan mendatangkan kemakmuran?" Berkata Tomaccae ri Luwuq: "Ditempatkan di Barat yang Barat, ditempatkan di Timur yang Timur, ditempatkan di Selatan yang Selatan, ditempatkan di atas yang atas, di bawah yang bawah."

"Apa yang membanyakkan orang, Nenek; mengembangbiakkan hewan? "Ia itu keteguhan hati. Empat jenis keteguhan itu. Pertama, tidak mengingkari janji dan tidak melangkahi persetujuan. Kedua, tidak mengurai barang jadi, serta tidak mengubah kesepakatan. Ketiga, jika ia mengadili, nanti berhenti setelah putus."

"Delapan bukti keteguhan itu. Pertama, tidak menambah-nambah perkataan. Kedua, tidak mengurangi perkataan. Ketiga, melaksanakan suruhan. Keempat, mengucapkan perkataan yang benar. Kelima, melakukan perbuatan yang bermanfaat. Keenam, melaksanakan pekerjaan yang berpatutan dengan katakatanya. Ketujuh, membantu orang lain sewajarnya. Kedelapan, merendah-rendah sepatutnya."

Kutipan wérékkada di atas menggambarkan keteguhan para leluhur masyarakat Bugis. Keteguhan itu akan diwariskan kepada anak cucunya lewat wérékkada yang dituturkan secara turun temurun, yang pertama pada kutipan di atas adalah sikap konsisten menempatkan sesuatu pada tempatnya. Kedua adalah konsisten terhadap keputusan yang pernah ditetapkan dan menuntaskan semua pekerjaan yang telah direncanakan, tidak bekerja sepotong-sepotong. Menurut mereka para leluhur bahwa apabila kesemuanya itu dilaksanakan dengan baik akan mendatangkan kemakmuran bagi rakyat dan bangsanya. Rakyat akan sejahtera dan ternak akan berkembang biak dengan baik.

\section{Sirik (harga diri)}

Sirik adalah suatu sistem nilai sosiokultural dan kepribadian yang merupakan pranata pertahanan harga diri dan martabat manusia sebagai individu dan anggota masyarakat. Secara singkat ia adalah pandangan hidup yang bertujuan untuk mempertahankan harkat dan martabat pribadi, orang lain atau kelompok, terutama negara (Hamid, 2005: 57). Berikut ditampilkan beberapa wérékkada yang berkaitan dengan sirik.

Makkedai torioloé: "Limai wuwangenna sappona wanuaé tennauttamaiwi toppé-gauq bawang. Séuani, lempu silaong adeq. Maduanna, rapanngé nasilaong getteng. Matellunna, waranié nasilaong acca. Maeppana, malaboé nasilaong palecé. Malimanna ripassaniasai éwa-ngeng pammusué, naripassilaong ada madécéng namalemma. Ajaq tawedding naottong uluada balitta. Ianaro gauq limaé wuwangenna ri assappoang wa-nua, ajaq naengka sakibanra tanaé. (Fachruddin, Lagausi, \& Nur, 1985: 14)

\section{Terjemahan}

"Berkata orang tua-tua, "Lima jenis pagar negeri sehingga tidak dimasuki orang yang berbuat sewenang-wenang. Pertama, kejujuran yang disertai adat. Kedua, ibarat yang disertai ketabahan. Ketiga, keberani-an disertai kepandaian. Keempat, tidak bathil disertai keramahan. Kelima, diper-siapkan peralatan perang disertai kata-kata yang baik dan lemah lembut. Hendaknya jangan kita ditekan dengan janji-janji oleh lawan. Itulah lima jenis tingkah laku pemagar negeri, sehingga negeri tidak mempunyai celah.”

Kutipan wérékkada di atas menggambarkan para leluhur masyarakat Bugis menitipkan pesan kepada anak cucunya agar senantiasa menjaga harkat dan harga diri negerinya agar tidak dimasuki oleh orang-orang yang akan mengacau. Jujur disertai adat, karena adat itulah yang memperbaiki orang banyak. Sedangkan orang jujur biasanya Tuhan berpihak kepadanya sehingga patut diperhitungkan. Ibarat disertai ketabahan. Bagi yang orang tabah 
biasanya tidak ada pekerjaan yang sulit dikerjakan, karena mereka telaten dan tidak cepat bosan. Berani disertai kepandaian. Orang berani biasanya pandai melihat situasi dan penuh perhitungan. Tidak sembarang bertindak, mereka memikirkan dengan cermat langkah-langkah apa yang ia tempuh sebelum bertindak. Walaupun sudah mempersiapkan alat-alat perang, mereka tetap ramah dan lemah lembut. Dibalik semua itu, harus tegas jangan mau ditekan dengan janjijanji dari pihak lawan.

“Teqbarang tau riala paréwa ri tanaé." Iapa nariala paréwa ri tanaé eppai mengkaiwi. Séuani malempui. Madu-anna kénawanawapi. Matellunna sugi-pi. Maeppana waranipi.

Naia tanranna tomalempué, Séuani ri asalaié naqdampeng. Maduanna ri parennuangié tennapacékoi. Matellunna temmangoaiéngi natania olona. Mae-ppana tennasesseq décénngé narékko alénami podécénngi.

Naia tanranna tokénawa-nawaé, eppa toi. Séuani méloriwi gauq patujué. Maduanna méloriwi ada patujué. Matellunna moloié roppo-roppo naré-weq. Maeppana molaélaleng namatikeq.

Naia tanranna tosugié, eppa toi. Séuani sugi ada-adai. Maduanna sugi nawa-nawai. Matellunna sugi akkarésoi. Ma-eppana sugi balancai.

Naia tanranna towaranié, eppa toi. Séuani tettaténré napoléi ada maja ada madécéng. Maduanna temmangkalingai karéba naéngkalinga toi. Matellunna temmétaui ripaqdiolo enrenngé ripak-dimunri. Maeppana temmataui mita bali." (Fachruddin, Lagausi, \& Nur, 1985: 27-28).

Terjemahan

"Tidak sembarang orang dijadikan alat negara. Seseorang dapat dijadikan alat negara, jika ia memiliki empat hal. Pertama ia jujur. Kedua, ia berfikir panjang. Ketiga ia kaya. Keempat, ia pemberani.

Adapun tanda orang jujur, pertama orang yang bersalah kepadanya, dimaafkan. Kedua, ia dipercaya dan tidak mengkhianat. Ketiga, tidak serakah terhadap yang bukan haknya. Keempat, tidak menuntut kebaikan jika hanya dia sendiri menikmatinya.

Adapun tanda orang yang berfikir panjang ada empat pula jenisnya. Pertama, ia menyukai perilaku yang benar. Kedua, ia menyukai perkataan yang benar. Ketiga, jika menghadapi semak belukar, ia kembali. Keempat, jika ia melalui jalan, ia berhati-hati. Adapun tanda orang kaya, empat pula jenisnya. Pertama, kaya perkataan. Kedua, kaya pikiran. Ketiga, kaya akan pekerjaan. Keempat, kaya belanja.

Adapun tanda orang berani, empat pula jenisnya. Pertama, ia tidak gentar menerima perkataan jelek dan perkataan baik. Kedua, tidak mendengar berita tetapi didengarkan juga. Ketiga, tidak takut ditempatkan di depan atau di belakang. Keempat, tidak takut menghadapi lawan."

Kutipan di atas menggambarkan para leluhur masyarakat Bugis yang memiliki harkat dan martabat dan akan diwariskan kepada anak cucunya. Menurut mereka hanya orang-orang yang bermartabat yang dapat dijadikan alat negara. Orang-orang bermartabat sekurangkurangnya memiliki kriteria seperti yang disebutkan dalam wérékkada di atas.

Orang jujur dimanapun berada pasti disenangi oleh orang lain. Mudah berkomunikasi dan bekerja sama dengan berbagai pihak karena dipercaya oleh orang lain. Tidak ba-nyak tuntutan secara pribadi, selalu memahami hak dan kewajibannya. Mereka bertindak dan bertutur sapa dengan sopan, tidak serampangan. Mereka memilki banyak ide dan kreatif. Tidak ada pekerjaan yang sulit baginya. Tidak mudah terjebak dengan berita-berita yang belum tentu kebenarannya. Selalu siap dimana saja akan ditempatkan.

"Makkedai torioloé: "Narékko balio ada, issenngi gaué siturué adek é, enrenngé saraq é, kuaé rapanngé, maka mottonngen énngi adanna taué, naia mupatettongi pabali ada. Apak iaritu natania balinna adanna taué muba-linngi, naécawa-cawaino, napoasseng toni déna tomacca ri wanuaé." (Fachruddin, Lagausi, \& Nur, 1985: 12).

\section{Terjemahan}

"Berkata orang tua-tua: "Jika engkau akan menjawab perkataan orang lain, ketahuilah terlebih dahulu adat baru menjawab. Carikanlah perbuatan yang sesuai dengan adat, syariat agama, serta hukum perumpamaan yang dapat mengatasi perkataan 
lawan. Itulah yang engkau jadikan landasan dalam menjawab perkataan orang lain. Apabila engkau salah menjawab pertanyaan mereka, engkau akan ditertawai dan mereka menganggap sudah tidak ada lagi orang pandai di dalam negeri."

Kutipan wérékkada di atas menggambarkan bahwa orang tua-tua masyarakat Bugis berpesan kepada anak cucunya agar senantiasa menjaga harkat dan martabat negerinya dengan berusaha semaksimal mungkin menjawab segala pertanyaan yang diajukan oleh negeri lain. Ia mengingatkan anak cucunya agar tidak dipermalukan oleh orang lain, sebab apabila tidak bisa menjawab pertanyaan mereka, mereka menganggap sudah tidak ada lagi orang pandai di dalam negeri. Oleh karena itu orang tua-tua berpesan agar adat dan syariat agama dijadikan sebagai landasan untuk menjawab semua pertanyaan yang diajukan orang lain. Orang tua-tua beranggapan bahwa adat dan syariat agama merupakan landasan jawaban yang paling baik.

Matinroé Ritanana berpesan kepada anak cucunya agar senantiasa menjaga harkat dan martabatnya dengan mempertahankan empat hal yang ada pada dirinya, yaitu pikiran, keadilan, harga diri, dan perbuatan baik. Pikiran yang dimaksud di sini adalah pikiran positif atau prasangka baik. Hindari sifat pemarah karena akan mengacaukan pikiran. Usahakan selalu bersikap adil dan menghindari kesewenangwenangan. Rasa malu atau harga diri harus dipertahankan, jangan serakah. Apabila sifat serakah sudah dimiliki pasti akan merugikan orang lain, karena hak-hak mereka pasti akan dilanggar dan jangan suka mempergunjingkan orang lain, karena tidak tertutup kemungkinan ada fitnah.

\footnotetext{
"Makkedai Arung Bila: "Naia barangkaukna makkarésoé, tellu toi wuwangenna. Séuani, nakkarésoanngi lisek bolana. Maduanna, nakkarésoiwi séajing sempanuanna. Matellunna, nakkarésoinna pakkasiwianna ri adek é, enrenngé ri arajanngé.

Iatonaro gauk é tellué wuwangenna riaseng onro ri adek. Apak taniasa riaseng onro appongeng madécénngé. Bettuanna madécénngé akbijangenna. Onro gauqmisa naseng adek é onro. Apak pettui adaé, makkedaé ia bicaraé dé buluna, dé lompoqna.
}

Dé ri awa, dé ri wawo. (Fachruddin, Lagausi, \& Nur, 1985: 210).

Terjemahan

"Berkata Arung Bila, [Kepala Pemerintahan Bila (nama daerah)]: Mengenai perbuatan tingkah laku, tiga pula bahagiannya. Pertama, bekerja untuk isi rumahnya. Kedua, bekerja untuk negeri dan sanak keluarganya. Ketiga, bekerja untuk baktinya kepada raja. Ketiga perbuatan itulah disebut kedudukan pada adat. Sebab bukanlah asal-usul yang baik disebut kedudukan. Artinya yang baik keturunannya. Kedudukan yang hanya berhubungan dengan perbuatan yang oleh adat disebut onro. Sebab setelah diputuskan, bahwa peradilan (hukum) tidak ada gunungnya, tidak ada lembahnya. Tidak ada di atas, tidak ada di bawah.”

Kutipan wérékkada di atas menggambarkan leluhur orang-orang Bugis sangat menjaga harkat dan martabatnya sebagai pemimpin dan bertanggung jawab di dalam rumah tangganya. Pertama, bekerja untuk isi rumahnya, maksudnya adalah ia sebagai kepala rumah tangga harus bertanggung jawab bekerja untuk menghidupi keluarganya. Kedua, bekerja untuk negeri dan sanak keluarganya, maksudnya ia bekerja di samping untuk keluarganya juga memberi pemasukan untuk negeri dan membantu sanak keluarganya yang lain. Ketiga, bekerja untuk baktinya kepada raja, maksudnya ia bekerja sebagai sumbangsihnya kepada pemegang tampuk pemerintahan.

\section{KESIMPULAN}

Wérékkada atau petuah-petuah leluhur merupakan salah satu jenis sastra lisan Bugis yang hingga saat ini masih tetap hidup dan dihayati, terutama mereka yang berlatar belakang budaya Bugis dan penutur bahasa Bugis. Dalam telaah susastra Bugis ini diungkapkan tiga kearifan lokal yang terdapat dalam wérékkada, yaitu:

1. Kejujuran. Kejujuran ini merupakan salah satu faktor yang sangat mendasar di dalam kehidupan khususnya dalam menjalin hubungan sesama manusia.

2. Keteguhan. Keteguhan ini adalah gambaran dari tingkah laku sehari-hari seseorang yang memiliki sikap tegas, tangguh, setia pada keyakinan, taat asas, dan memiliki harga diri yang tinggi. 
3. Sirik. Sirik atau harga diri adalah pandangan hidup yang bertujuan untuk mempertahankan harkat dan martabat pribadi, orang lain atau kelompok dalam budaya Bugis.

Jenis sastra lisan ini merupakan warisan leluhur orang Bugis yang disampaikan secara turun temurun, dari satu generasi ke generasi berikutnya. Oleh karena itu, perlu usaha untuk mencegah kepunahannya dengan cara melakukan penginventarisasian sastra lisan maupun melalui penelitian yang lebih mendalam dan menyeluruh.

Petuah-petuah leluhur yang terkandung dalam "wérékkada" pada dasarnya masih relevan dengan kehidupan sekarang yang juga menjadi salah satu pencerminan kearifan lokal masyarakat Bugis. Karena itu, kearifan lokal sebagai jati diri bangsa perlu direvitalisasi, khususnya bagi generasi muda dalam percaturan global saat ini dan di masa mendatang. Dengan demikian, identitas sebagai bangsa baik secara fisik maupun non-fisik akan tetap terjaga. Pengungkapan tiga kearifan lokal di dalam kajian ini bukanlah berarti bahwa hanya itu yang ada. Maka dari itu, kajian lanjutan masih tetap diperlukan.

\section{Ucapan Terima Kasih}

Penulis mengucapkan terima kasih kepada semua pihak yang telah membantu dalam penyusunan tulisan ini. Penulis juga mengucapkan terima kasih kepada Kapata Arkeologi yang berkenan mempublikasikan tulisan ini sebagai karya ilmiah.

$* * * * *$

\section{DAFTAR PUSTAKA}

Alwi, H., \& Sugono, D. (2011). Politik Bahasa. Jakarta: Badan Pengembangan dan Pembinaan Bahasa Kementerian Pendidikan dan Kebudayaan.

Endraswara, S. (2011). Metodologi Penelitian Sastra; Epistemologi, Model, Teori, dan Aplikasi. Yogyakarta. Cops.

Fachruddin, A. E., Lagausi, K., \& Nur, H. (1985). Pappasenna to Maccae ri Luwuq Sibawa Kajao Laliqdong ri Bone: transliterasi dan terjemahannya kedalam bahasa Indonesia. Ujung Pandang: Departemen Pendidikan dan Kebudayaan, Proyek Penelitian dan Pengajian Kebudayaan Sulawesi Selatan LaGaligo.
Hall, S. (1979). Budaya, Media, Bahasa: teks utama pencanang cultural studies 1972-1979 Culture, Media, Language. Yogyakarta: Jalasutra.

Hamid, A. (2005). Siri' dan Pesse' Harga Diri Manusia Bugis, Makassar, Mandar, Toraja. Makassar: Pustaka Refleksi.

Harianto. (2004). Burung Arue dan Burung Talokot. Kumpulan Cerita Rakyat Kalimantan Barat. Jakarta: Pusat Bahasa Depdiknas.

Jemmain. (2016). Wérékkada Salah Satu Pencerminan Kearifan Lokal Masyarakat Bugis. In Bunga Rampai: Hasil Penelitian Bahasa dan Sastra. Makassar: Balai Bahasa Sulawesi Selatan.

Marihandono, D. (2015). Memanfaatkan Karya Sastra Sebagai Sumber Sejarah. In Stella Rose (Ed.), Prosiding Sastra dan Solidaritas Bangsa (pp. 81-91). Ambon: Kantor Bahasa Maluku.

Mustafa. (2016). Nilai dan Manfaat yang Terkandung dalam Silasa I. Jurnal Gramatika, III(1), 1018.

Pradopo, R. D. (2003). Prinsip-prinsip Kritik Sastra. Yogyakarta: Gadjah Mada University Press.

Said, M. (2015). Kearifan Lokal dalam Sastra Bugis Klasik. Retrieved September 29, 2017, from http://www.wacana.co/

Sikki, M. (1995). Nilai dan Manfaat Pappaseng Sastra Bugis. Ujung Pandang: Bagian Proyek Pembinaan Bahasa dan Sastra Indonesia dan Daerah Sulawesi Selatan.

Syamsudduha. (2012). Pendidikan Nilai dan Karakter dalam Pappaseng: Refrsentatif Norma dan Falsafah Hidup Masyarakat Bugis. In Prosiding Kongres Internasional II Bahasa-bahasa Daerah Sulawesi Selatan (pp. 310-321). Makassar: Balai Bahasa Provinsi Sulawesi Selatan dan Provinsi Sulawesi Barat.

Tang, M. R. (2012). Sastra Bugis Sebagai Dokumen Budaya. In Prosiding Kongres Internasional II Bahasa-bahasa Daerah Sulawesi Selatan (pp. 60-65). Makassar: Balai Bahasa Provinsi Sulawesi Selatan dan Provinsi Sulawesi Barat.

Uniwati. (2012). Nilai-Nilai Kearifan Lokal Pantun Sindiran (Apparereseng) Bugis: Tinjauan Hermeneutik. In Prosiding Kongres Internasional II Bahasa-bahasa Daerah Sulawesi Selatan (pp. 322-329). Makassar: Balai Bahasa Provinsi Sulawesi Selatan dan Provinsi Sulawesi Barat.

Wellek, R., \& Warren, A. (1993). Teori Kesusastraan. Jakarta: Gramedia. 